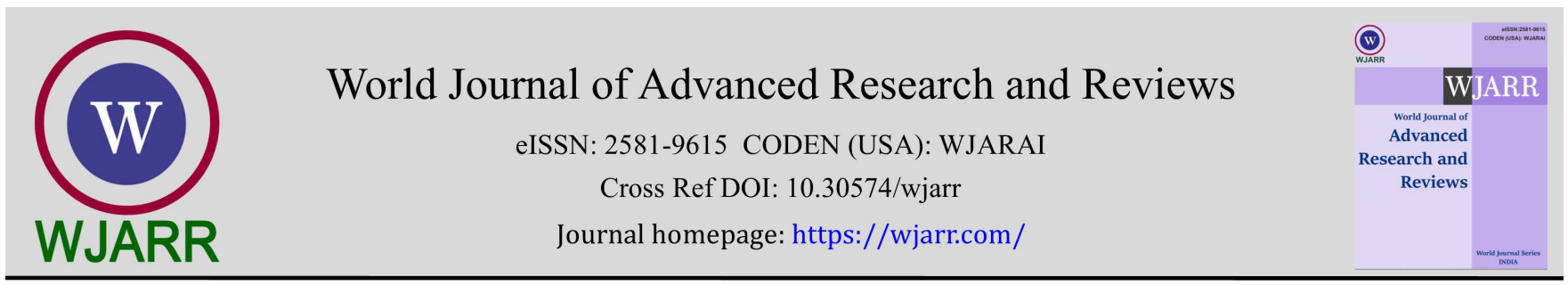

(RESEARCH ARTICLE)

Check for updates

\title{
Challenges of human resource information system adoption: Evidence from two Ghanaian tertiary institutions
}

\author{
Kwesi Aseredum Hagan 1, ${ }^{*}$, Bridget Elorm Lotsu ${ }^{2}$, Ernest Worlanyo Hodowu ${ }^{3}$ and Daniel Abaka-Yawson ${ }^{4}$ \\ ${ }^{1}$ Teaching and Examinations Unit, University of Health and Allied Sciences, Ho, Ghana. \\ 2 Procurement Unit, University of Health and Allied Sciences, Ho, Ghana. \\ ${ }^{3}$ School of Public Health, University of Health and Allied Sciences, Ho, Ghana. \\ ${ }^{4}$ University College of Management Studies, Accra, Ghana.
}

World Journal of Advanced Research and Reviews, 2022, 13(02), 346-349

Publication history: Received on 28 November 2021; revised on 03 February 2022; accepted on 05 February 2022

Article DOI: https://doi.org/10.30574/wjarr.2022.13.2.0111

\begin{abstract}
Human Resource Information System (HRIS) is one of the most important Management Information Systems (MIS) which contribute to human resource service delivery of an organization. This study therefore, seeks to identify challenges associated with the process. A closed-ended questionnaire was administered to 63 respondents from the University of Health and Allied Sciences (UHAS) as well as Ho Technical University (HTU) to identify these challenges. The study found lack of management support as the major challenge to the adoption of Human Resource Information System (HRIS). The study concludes that that lack of management support slows down the adoption of HRIS. It is therefore suggested that management should be involved and sensitized on the importance of HRIS to improve and enhance its adoption.
\end{abstract}

Keywords: Tertiary Institutions; Ho; Human Resource; Information System

\section{Introduction}

Management Information System (MIS) presents as a crucial contributor to human resource service delivery of an organization. Human Resource Information Systems (HRIS) helps in the acquisition, storage, manipulation, analysis, retrieval, and distribution of information relating to human resources [1]. HRIS helps organizations by automating most of the human resource planning functions. The system has become an important strategic tool since it collects, manages and reports information for decision-making.

Despite a great effort by the management and the heavy investments that has been made on the information technologybased reforms at the various universities, implementation of HRIS still appears to be a serious challenge [1]. Even though studies have been done on HRIS [1] [2] [3], no such studies have investigated HRIS within the Ghana public educational sector. Specifically, no attention has been given to establish the factors contributing to the sluggish adoption of the system at the University of Health and Allied Sciences and the Ho Technical University. This study therefore, seeks to address this gap in knowledge by establishing perceived factors influencing the adoption of HRIS at the stated universities and challenges associated with the process.

\footnotetext{
${ }^{*}$ Corresponding author: Kwesi Aseredum Hagan

Teaching and Examinations Unit, University of Health and Allied Sciences, Ho, Ghana.

Copyright $(2022$ Author(s) retain the copyright of this article. This article is published under the terms of the Creative Commons Attribution Liscense 4.0.
} 


\section{Methods}

\subsection{Study Design and Sampling Technique}

An explanatory design was used to assess the knowledge about the determinants of HRIS from respondents from two tertiary institutions i.e., University of Health and Allied Sciences and the Ho Technical University, both in Ho using a closed-ended questionnaire. The population of this study is made up of staffs at the Human resource divisions and the Information, Communication and Technology division of each university. Information acquired from the HR directorate at HTU indicates a staff strength of at the HR department of 12 and the IT department has a staff strength of 17 . With respect to UHAS, data available indicates an HR staff strength of 18 and ICT staff strength of 28 people. The study therefore has a total population size of 75 employees from the HR and ICT department of both universities.

\subsection{Data Collection Procedure}

The data was collected through the use of a self-administered questionnaire manually by the researchers to ensure a high response rate. The data was collected over a period of three months between August and September, 2019. Data collected from the questionnaires was standardized such that each respondent got the same question. Returned questionnaires were edited to correct probable errors and to sort out misconceptions and misunderstandings to ensure credibility of the research. In order to collect and organize data in such a manner that was acceptable and later used to conduct the required analysis. A total of 63 respondents filled and returned their questionnaires, representing an $84 \%$ response rate.

\subsection{Data Processing and Analysis}

Data obtained was compiled and analysed using Statistical Package for Social Sciences (SPSS) version 22.0. Descriptive statistics such as percentages and frequencies were used to analyse socio-demographic characteristics. Linear regression, means and standard deviations were used to analyse various data were necessary. P-value less than 0.05 was considered statistically significant.

\section{Results and discussion}

\subsection{Descriptive Results for Socio-Demographic Characteristics}

Table 1 shows various socio-demographic characteristics of respondents. Majority of the respondents were males $46(73 \%)$, in the age range of 31-40 years $45(71 \%)$ and had first degree as their highest educational attainment $39(62 \%)$.

Also, a good number of the respondents were junior staff 31(49\%), had worked for 5-9 years 46(73\%) and work in the human resource department of their institution.

Table 1 Socio-demographic Characteristics of the Respondents

\begin{tabular}{|c|c|c|}
\hline Background characteristics & Frequency & Percentage (\%) \\
\hline \multicolumn{3}{|l|}{ Sex } \\
\hline Male & 46 & 73 \\
\hline Female & 17 & 27 \\
\hline Total & 63 & 100 \\
\hline \multicolumn{3}{|l|}{ Age (in years) } \\
\hline $21-30$ & 12 & 19 \\
\hline $31-40$ & 45 & 71 \\
\hline $41-50$ & 5 & 8 \\
\hline $51-60$ & 1 & 2 \\
\hline \multicolumn{3}{|l|}{ Academic qualification } \\
\hline Postgraduate Degree & 14 & 22 \\
\hline First Degree & 39 & 62 \\
\hline
\end{tabular}




\begin{tabular}{|l|c|c|}
\hline HND & 2 & 3 \\
\hline Professional Certificates & 8 & 13 \\
\hline Level of Staff \\
\hline Junior Staff \\
\hline Senior Staff & 31 & 49 \\
\hline Senior Member & 20 & 32 \\
\hline Years of work & 12 & 19 \\
\hline 1 to 4 years & 15 & 24 \\
\hline 5 to 9 years & 46 & 73 \\
\hline 10 and above & 2 & 3 \\
\hline Department & 37 & 59 \\
\hline Human Resource & 26 & 41 \\
\hline IT & \\
\hline
\end{tabular}

\subsection{Challenges associated with HRIS adoption}

The perception of the respondents was sought to identify challenges associated with HRIS adoption. Table 2, indicates the response from respondents as to the challenges they associate with HRIS adoption. They showed their concerns with respect to various statements concerning the challenges they face. The results are discussed using mean and their standard deviation. Bakker [4] have established that overall mean values within the range of 1.00-2.32 indicates a low level of acceptance and an overall mean value between 2.33-3.66 signifies a moderate level of acceptance whiles overall mean values between 3.67-5.00 indicates a high level of acceptance. The findings were descriptively summarised with mean scores as well as the respective standard deviation scores. The results are presented in Table 2.

Table 2 Challenges of HRIS Adoption at UHAS and HTU

\begin{tabular}{|l|c|c|}
\hline Statement & Mean & Std. Dev \\
\hline Lack of management support acts as a barrier to the adoption of HRIS & 4.613 & 0.49 \\
\hline HRIS is costly to implement and sustain & 4.597 & 0.59 \\
\hline Low level of importance credited to HR functions in general & 4.387 & 0.73 \\
\hline Lack of reliable vendor frustrate adoption of HRIS & 4.317 & 1.02 \\
\hline IT firms lack the technical expertise to adopt HRIS & 3.645 & 1.43 \\
\hline HRIS adoption face resistance from employees & 3.307 & 1.48 \\
\hline \multicolumn{2}{|r|}{ Source: Field survey (2019) } \\
\hline
\end{tabular}

Table 2 indicates that respondents strongly agreed or agree that lack of management support acts as a barrier to the adoption of HRIS ( $M=4.613, S D=0.49)$. This agrees with that of Ang, Davies and Finlay, [5] who posited that there is always a challenge when management are to show their support to HRIS Adoption. It was also revealed that majority of the respondents strongly agree or agree that HRIS is costly to implement and sustain in an organisation (M=4.597, $\mathrm{SD}=0.059$ ). The findings are in agreement with Heeks, [6] who postulated that HRIS is costly to implement and mostly there are funds at the department to support it.

Again, it was interesting to identify that respondents agreed that Low level of importance credited to HR functions in general $(M=4.317, S D=1.02)$. The findings are supported Budhwar and Bhatnagar [7] who stated that HR has traditionally operated in "reactive mode" in the corporate sector, which means that the HR functions are brought into the picture only when there is a need. Furthermore, it was found that respondents also agreed that Lack of reliable vendor frustrate adoption of HRIS (M=4.317, $\mathrm{SD}=1.02)$. This is in line with the findings of Huang and Palvia, [8] who posited that when there is no reliable vendor of HRIS, adoption of HIRS is affected negatively.

Last but not the least, it was found that respondents agreed that when IT firms lack the technical expertise to adopt HRIS it becomes a challenge of HRIS Adoption ( $M=3.645, \mathrm{SD}=1.43)$. It shows that the respondents hovers around agreed 
and neutral. This is supported by Teo, Lim, and Fedric [9], an organization's IT experience over time in the HR department has been found to have a strong effect on the overall success of HRIS adoption in an organization. Finally, it was found that respondents also agreed that HRIS adoption face resistance from employees ( $M=3.307, S D=1.48)$. This is the least of all the challenges questions that were asked during the data collection period. This is concreted by Bader [10] who also posited resistance to change affect HRIS Adoption.

\section{Conclusion}

The study concludes that lack of management support slows down the adoption of HRIS.

\section{Recommendations}

It is therefore suggested that management should be involved and sensitized on the importance of HRIS to improve and enhance its adoption.

\section{Compliance with ethical standards}

\section{Acknowledgments}

The authors are grateful to the staff of the University of Health and Allied Siences, Ho as well as the Ho Technical University for their participation and keen interest in the study.

\section{Disclosure of conflict of interest}

The authors declare that no conflict of interest exist.

\section{Statement of informed consent}

Informed consent was obtained from all individual participants included in the study.

\section{References}

[1] Nagrenda A. The Impact of Organizational Culture on the Adoption of E Management. International Journal of Business and Management. 2014; 9(9): 1833-8119.

[2] Alhazemi A. Critical Analysis and Current Challenges Facing HRIS Adoption in Arab Countries-the Case of Saudi Arabia. International Journal of Heritage, Tourism and Hospitality. 2017; 11(2): 143-164.

[3] Marlene SAS, Carlos GSL. The Role of Information Systems in Human Resource Management, Management of Information Systems, Maria Pomffyova, Intech Open. December 21st 2017.

[4] Bakker Y. Back to the future of human resource information systems? A survey towards the role of country differences regarding adoption and deployment outcomes of e-HRM. 2010.

[5] Ang C, Davies MA, Finlay PN. An empirical model of IT usage in the Malaysian public sector, The Journal of Strategic Information Systems. 2001; 10(2): 159-174.

[6] Heeks R. Information systems and developing countries: Failure, success, and local improvisations. The information society. 2002; 18(2): 101-112.

[7] Budhwar PS, Bhatnagar J. The Changing Face of People Management in India, Taylor \& Francis. 2009.

[8] Huang Z, Palvia P. ERP implementation issues in advanced and developing countries, Business Process 9 Management Journal. 2001; 7(3): 276-284.

[9] Teo, T. S., Lim, G. S., \& Fedric, S. A. (2007). The adoption and diffusion of human resources information systems in Singapore. Asia Pacific Journal of Human Resources, 45(1), 44-62.

[10] Bader YO. The relationship between human resource information system (HRIS) functions and human resource management (HRM) functionalities. Journal of Management Research. 2012; 4(4): 192-211. 